\title{
CrimRxiv
}

\section{Asylum claims based on sexual orientation: a review of psycho-legal issues in credibility assessments}

Hedayat Selim, Julia Korkman, Elina Pirjatanniemi, Jan Antfolk

Published on: Feb 25, 2022

DOI: $10.21428 / \mathrm{cb} 6 \mathrm{ab} 371.4 \mathrm{f} 5087 \mathrm{bb}$

License: Creative Commons Attribution 4.0 International License (CC-BY 4.0). 
